\title{
SÍNDROME CONGÊNITA DO ZIKA VÍRUS: EXPERIÊNCIAS MATERNAS
}

\author{
CONGENITAL ZIKA VIRUS SYNDROME: MATERNAL EXPERIENCES
}

\begin{abstract}
RESUMO
O trabalho teve como objetivo analisar as experiências sobre o cuidar, relatadas por mães de pessoas com deficiência múltipla. Este artigo é um recorte da pesquisa "Mães de Pessoas com Deficiência Múltipla: experiências vividas no itinerário do cuidar" na qual afirmamos que, enquanto experiência de formação humana e dimensão educativa, o cuidado tem sido ignorado. $O$ ato de cuidar é a capacidade de interação do sujeito com o outro, o que exige a identificação de suas necessidades, aprendizagens específicas e habilidades diversas. A partir da pesquisa com o8 mulheres que, provavelmente, foram contaminadas pelo Zika vírus, refletimos sobre deficiência, cuidado e a relação de interdependência vivenciada pela família. O método adotado foi a História Oral, abordagem qualitativa e os instrumentos de coleta de dados foram questionário e entrevista. Foi evidenciado que o cuidado foi/é naturalizado como algo feminino o que torna as cuidadoras invisíveis frente à igualdade de direitos.
\end{abstract}

Palavras-chave: Gênero. Cuidado. Maternagem. Deficiência. Proteção social. Direitos humanos.

\begin{abstract}
The objective of this work was to analyze the experiences about caring, reported by mothers of people with multiple disabilities. This article is a clipping of the master's research "Mothers of People with Multiple Disabilities: experiences lived in the caring itinerary" where we affirm that as an experience of human formation and educational dimension, care has been ignored. The act of caring is the subject's ability to interact to other person, which requires the identification of their needs, specific learning and diverse skills. From the research done with o8 women who were probably infected by the Zika virus, we reflect on disability, care and the interdependence relationship experienced by the family. The method adopted was Oral History, a qualitative approach and the data collection instruments were a questionnaire and an interview. It was evidenced that care was / is naturalized as something feminine, which makes caregivers invisible in the face of equal rights.
\end{abstract}

Keywords: Gender. Caring. Maternity. Deficiency. Social protection. Human rights.

Karla Muniz Belém

Secretaria de Educação do Estado da Bahia. E-mail: kmbelem@gmail.com

Luciene Maria da Silva

Universidade do Estado da Bahia (UNEB). E-mail: lucienemariao5@gmail.com 


\section{Introdução}

No primeiro semestre de 2015, no Brasil, surtos de uma doença exantemática ${ }^{1}$ aguda, parecida com a Dengue, surgiram nas cidades de Natal (RN) e Salvador (BA). Pouco depois, outros estados também confirmaram a transmissão autóctone ${ }^{2}$ da infecção por Zika vírus. O segundo semestre chega com a percepção do aumento dos casos de microcefalia, principalmente no Nordeste do país, em especial na Paraíba, Pernambuco e Ceará (FEITOSA; FACCINI; SANSEVERINO, 2016). A microcefalia congênita não é a doença, mas um sinal neurológico importante de que algo está dificultando o crescimento do cérebro.

Em resposta ao aumento de ocorrências de microcefalia no Brasil, o Ministério da Saúde (MS) declara Emergência em Saúde Pública de Importância Nacional ESPIN3 de 2015-2017 (BRASIL, 2015). Entre os anos 2015 e 2018, foram notificados, no Brasil, 16.90o casos suspeitos de alterações no crescimento e desenvolvimento, possivelmente, relacionados à infecção pelo vírus Zika e outras etiologias infecciosas. A maioria dos casos (58,6\%) foi notificada no Nordeste do país, tendo maior impacto nos estados de Pernambuco, Bahia e Paraíba (BRASIL, 2018). No ano de 2020, segundo dados do Ministério da Saúde, foram notificados 468 casos suspeitos de bebês para Síndrome Congênita do Zika vírus (SCZ).

A epidemia de Zika evidencia questões como a pobreza e as desigualdades de gênero, pois adiciona responsabilidade às mulheres no cuidado para com a criança, consequentemente, reduz a participação feminina no mundo do trabalho e pode impactar negativamente o bem-estar psicológico. As famílias pobres estão não só mais vulneráveis à infecção pelo Zika vírus, mas também pagam um custo elevado em termos de orçamento doméstico, saúde e qualidade de vida, pois podem não ter os recursos necessários para buscar os cuidados e o apoio adequados.

Assim, existe desigualdade de gênero, tanto na esfera pública quanto na privada, nas relações de cuidado que, frequentemente, se materializam na mulher; é ela quem se dedica em cuidar. Apesar dos avanços da mulher no mercado de trabalho, a Pesquisa Nacional por Amostra de Domicílios Contínua (PNAD C) aponta que as mulheres superam os homens e ocupam profissões culturalmente femininas, associadas a menores salários; a maior disparidade é na categoria de emprego doméstico, na qual 92,3\% são mulheres (IBGE, 2018). Mas elas estão presentes também no magistério, nas enfermarias e na assistência social. Ou seja, as mulheres

\footnotetext{
1 Exantema é uma erupção geralmente avermelhada que aparece na pele devido à dilatação dos vasos sanguíneos ou inflamação. Disponível em: https://site.medicina.ufmg.br/observaped/exantemadoenca-exantematica/. Acesso em: 18 set. 2018.

2 Autóctone significa que se origina do lugar onde é encontrado, onde se manifesta. Disponível em: https://houaiss.uol.com.br/pub/apps/www/v3-3/html/index.php\#13. Acesso em: 25 jan. 2019.

3 A Organização Pan-Americana da Saúde (OPAS), em dezembro de 2015, publica o primeiro "Alerta epidemiológico: síndrome neurológica, malformações congênitas e infecção por vírus Zika. Implicações para a saúde pública nas Américas", ea Organização Mundial da Saúde (OMS), em o1 de fevereiro de 2016, declara "Emergência em Saúde Pública de Importância Internacional" (OPAS; OMS, 2016). O fim das Emergências Internacional e Nacional foi declarado nos dias 18/11/2016 e 11/05/2017, respectivamente.
} 
se ocupam, geralmente, em atividades que envolvem o cuidado. Logo, cuidam tanto na atividade laboral quanto no ambiente doméstico.

A evolução das relações familiares perpassa pelos valores dominantes e os imperativos sociais de cada época. A distinção entre as esferas privada e pública, em que a mulher é a responsável pelo lar e o homem é encarregado de prover o sustento (ARENDT, 2016), parece ainda não ter possibilitado, na sociedade contemporânea, a valorização das diferentes atividades exercidas por homens e mulheres. Sendo assim, o cuidado, frequentemente, é um dos tipos de trabalho e preocupação conferidos às mulheres, apesar da luta feminista pela desnaturalização dos papéis idealizados pela sociedade.

Na nossa cultura, o corpo feminino administra uma nova forma de gestação, nada fica ao acaso, o corpo que concebe necessita planejar rigorosamente a gravidez com o desejo de que nada ocorra fora do engendrado. O filho ou a filha perfeita(o) é resultado de muito trabalho materno. Assim, a epidemia de Zika vírus acaba por provocar na mulher grávida medo de uma gestão com malformação; e a angústia materna ao receber o diagnóstico de que gerou uma criança com múltiplas deficiências, pode afetar a maternagem, ou seja, o cuidado e o vínculo emocional que uma mãe investe no bebê após o nascimento pode ficar comprometido, pois o afeto é fundamental para uma boa maternagem.

O nascimento do diferente, não passa despercebido, sentimentos (medo, choque, angústia, insegurança, susto) ameaçam e desorganizam toda a estrutura familiar, pois a deficiência escapa do comum e do usual, quebrando a promessa do perfeito e do belo. É necessário elaborar o luto pelo filho idealizado para que a família não fique presa à melancolia e possa estabelecer o vínculo com a criança e não com a deficiência. Assim, o acolhimento da família ao receber um bebê com deficiência faz diferença, de forma positiva ou negativa, nas relações sociais que serão vivenciadas por eles. De acordo com Petean e Murata (2000):

O impacto é tão grande que compromete o estabelecimento de vínculo, a aceitação do filho a compreensão das informações, e perceber-se-á alteração na rotina diária, nos sonhos e projetos de cada membro da família, que se desestrutura sendo necessário longo processo para que retome o equilíbrio (PETEAN; MURATA, 2000, p. 41).

A dependência exige que a mãe/cuidadora funcione como um dispositivo para suprir as necessidades físicas e afetivas da criança, as quais, por vezes, são sentidas como se fossem suas. Tal condição exige um cuidado especializado e dedicado, plenamente identificado com o sujeito. O seu tempo é utilizado para atender às atividades de cuidado de vida diária, na espera de atendimentos médico e terapêutico, na busca de remédios e fraldas, entre outras atividades. Sem dúvida, a individualidade materna não deveria ser perdida com o nascimento do filho, a deficiência não deveria se tornar o centro da vida do filho e da mãe. 
O tempo delas parece ser o tempo infernal, como descrito por Benjamin (1994), "em que transcorre a existência daqueles a quem nunca é permitido concluir o que foi começado". Alimentar, dar banho, cuidar da casa, levar a criança à fisioterapia, à fonoaudiologia, depois à terapia ocupacional, e isso se repete diariamente. Que tempo essa mãe/cuidadora tem para ser mulher? Em que momento a mãe se relaciona com o filho e não com a deficiência? Em uma sociedade na qual a racionalidade serve de justificação e impedimento da autonomia, em que medida a experiência, para essas mães, não foi obstada pela necessidade de sobrevivência ou de autoconservação?

A autonomia e a emancipação tão perseguidas pelos indivíduos provocaram o efeito reverso: a impossibilidade de se lançar a novas experiências. Benjamin (1994) denuncia o empobrecimento da experiência, ao mesmo tempo que indica a urgência de sua reconstrução. $\mathrm{O}$ autor anuncia que os tempos modernos enfraqueceram o Efahrung (experiência), em detrimento da Erlebnis, a vivência.

A experiência, para Larrosa (2018, p. 18), "é o que nos passa, o que nos acontece, o que nos toca”. Assim, uma das condições para que ocorra a experiência é sentir e presenciar o que se passa. Contudo, este tipo de saber, atualmente, está perdendo espaço e relevância, frente à sociedade administrada que tudo organiza "para que nada nos aconteça" (LAROSSA, 2018, p. 18).

Desse modo, para acontecer a experiência é preciso que haja reflexão, ou seja, o sujeito se constitui em correspondência com o objeto, logo, a experiência é pessoal e coletiva. O sujeito e o objeto não podem ser compreendidos separadamente, pois isso negaria o que existe de subjetivo no objeto e o que há de objetivo no sujeito. Neste deslocamento está contida a experiência que presume a reflexão sobre o objeto e a autorreflexão do sujeito.

Assim sendo, o contato é característico ao fenômeno da experiência, mas, com o pensamento preso à vida imediata, o sujeito perde a capacidade de refletir sobre o objeto. Visto que a modernidade reivindica um indivíduo frio e indiferente, o que o torna cambiável e substituível, como uma necessidade de se autoconservar. Consequentemente, o conhecimento não ultrapassa ao imediatamente dado, fica submetido à adaptação e à autoconservação.

Horkheimer (2015, p. 129) afirma que "adaptar-se significa tornar-se igual ao mundo dos objetos para fins de autopreservação ${ }^{4}$. Esse tornar-se igual ao ambiente, de forma deliberada (em vez de reflexiva), é um princípio universal da civilização". Portanto, a autoconservação que deveria preservar a humanidade ganha dimensão dominadora, pois a eliminação das relações sociais de dominação pelo avanço das forças produtivas não se confirmou, tornando-se sinônimo de lucratividade. O que não precisaria desaparecer se a vida em sociedade fosse justa.

A autoconservação, portanto, pode impedir a experiência, pois reduz o distanciamento com a realidade para uma abertura sensível aos objetos, pois serve de proteção contra o sofrimento. São ações inconscientes, mesmo que sejam absurdas. A

4 Os termos autopreservação e autoconservação nesse texto são utilizados como sinônimos. 
urgência da situação pode impossibilitar a mãe/cuidadora de refletir sobre o objeto, como também sobre si própria, restando-lhe apenas a adaptação à situação existente. Então, "a abstração é o meio de uma razão autoconservadora" (ADORNO, 2009, p. 154).

Segundo Crochík (2003, p. 17), "como a felicidade, a liberdade e a justiça são atreladas, nos dias que correm, à adaptação e não à sua superação, que exige a superação da atual sociedade, elas têm o seu conteúdo reduzido ao que é possível no presente". Portanto, para essas mães parecem existir apenas os sonhos que sobrevivem à imposição da autoconservação, ou seja, para se preservarem, estas mulheres se voltam a atender todas as necessidades dos(as) filhos(as) com a finalidade de reabilitálos(as), colocam de lado suas vontades e impulsos, pois sabem que possivelmente não conseguirão realizá-los. Logo, a autoconservação serve de proteção contra o sofrimento.

Dessa forma, as relações entre os que cuidam e os que são cuidados, frequentemente, são desiguais, pois existe certo grau de dependência. A sociedade capitalista parece determinar que as pessoas estejam voltadas para ela ou para o cuidado, ou seja, os homens no mundo dos negócios e as mulheres no lar, direcionadas a cuidar. Assim, o status social é valorizado levando-se em consideração a vida pública e não a privada; logo, a cidadania da mulher é parcial.

Tronto (1997) chama a atenção para a necessidade de separar os aspectos femininos e feministas do cuidado. A autora afirma que "a abordagem feminina do cuidar carrega o fardo da aceitação das divisões tradicionais de gênero numa sociedade que desvaloriza o que as mulheres fazem", enquanto que a abordagem feminista amplia a compreensão do significado de cuidar do outro, "em termos morais e em termos de restruturação de instituições políticas e sociais mais amplas" (TRONTO, 1997, p. 200). Nesse aspecto, o cuidado deixa de ser restrito ao ambiente privado e passa a abranger as configurações das instituições políticas e sociais.

Assim, há a necessidade de uma mudança, pois o cuidado direcionará a sociedade para ser a mais democrática possível. Dessa forma, é necessário verificar como o cuidado se relaciona na natureza da teoria política democrática.

Todos os seres humanos necessitam de cuidado. Um ponto fundamental de acordo com Gilligan (2013, p. 54) é que "cuidados e assistência não são questões da mulher; são interesses humanos". O cuidado como uma necessidade humana, dissocia a mulher do enquadramento patriarcal no qual as qualidades do homem estão ligadas à justiça e à razão, e vincula a imagem da mulher às emoções, ou seja, ao cuidado. Esta divisão permite aos homens serem descuidados e omissos em prol dos direitos e da liberdade, enquanto a mulher renuncia a seus direitos em função de manter a paz e os relacionamentos. É irracional afirmar que os homens não possuem emoções e as mulheres não têm senso de justiça. Logo, ao pensarmos no cuidado como algo supérfluo, e não uma necessidade de todos os seres humanos, retiramos o direito à cidadania e à participação na sociedade das pessoas que necessitam do cuidado de forma vital. 


\section{Deficiência e cuidado}

A tessitura histórica sobre a deficiência não é linear, sofre várias tensões e rupturas ao longo do tempo. A cada época a pessoa com deficiência é vista de forma distinta. Influências externas à família foram as principais responsáveis pela (des) construção destas relações. Na Idade Média, a pessoa com deficiência era categorizada como monstro. Conforme Piccolo e Mendes (2012, p. 32), "o corpo definido como monstro propicia os sentimentos mais diversos na sociedade, desde o riso e a chacota, até o medo e o encantamento".

A fluidez da sociedade capitalista produz uma variação de identidades permeadas de relações de poder, que define os padrões de inclusão e exclusão social na busca do corpo produtivo e útil, o qual passa a ser visto do ponto de vista biológico e médico, ou seja, o corpo desviante só poderá ser corrigido pela prática médica. Velho (2012, p. 20, grifo do autor) explica a ideia de desvio como a "existência de um comportamento médio ou ideal, que expressaria uma harmonia com as exigências do funcionamento social".

Em razão disso, a medicina se apropria do corpo com impedimento determinando os padrões de normalidade. Ademais, deficiência não se restringe a doenças e lesões, "é um conceito que denuncia a relação de desigualdade imposta por ambientes com barreiras a um corpo com impedimentos" (DINIZ; BARBOSA; SANTOS, 2009, p. 65). Esse conceito foi construído por estudiosos da primeira geração do modelo social da deficiência, movimento que surgiu no Reino Unido nos anos 1970. Os estudiosos propuseram também a distinção entre lesão e deficiência, segundo a qual "a lesão seria um dado corporal isento de valor, ao passo que a deficiência seria o resultado da interação de um corpo com lesão em uma sociedade discriminatória” (DINIZ, 2012, p. 18).

Apesar disso, a deficiência ainda é responsabilidade do próprio indivíduo, sendo, portanto, de domínio privado, o que significa ser excluído de coisas indispensáveis à condição humana. Ou seja, a pessoa com deficiência é privada de manter relações com a realidade. Arendt (2016) explica que o domínio público só deixa vir à luz coisas que são consideradas relevantes de serem vistas ou ouvidas, o que é irrelevante é tratado como assunto privado. Para a autora, na privação o homem não existe, o que realiza não tem importância ou consequência para os outros e o que tem relevância para ele é isento de valor para os outros:

[...] a sociedade espera de cada um dos seus membros certo tipo de comportamento, impondo inúmeras e variadas regras, todas elas tendentes a "normalizar" os seus membros, a fazêlos comportarem-se, a excluir a ação espontânea ou a façanha extraordinária (ARENDT, 2016, p. 50, grifo da autora). 
Desvelar a conexão entre deficiência e cuidado é mostrar que as relações de dependência são inevitáveis à vida humana. Ao mesmo tempo, significa expor que o cuidar do outro tem ligação com o cuidar de si, para que a pessoa que cuida não submeta nem seja submetida a um vínculo de dependência, no qual o cuidador se anula colocando o interesse do outro acima do seu. É preciso não perder de vista a individualidade de quem cuida e de quem é cuidado. Desta maneira, para cuidar, é preciso estar atento às necessidades do outro e isso envolve empenho de tempo e esforço, o qual pode custar um alto preço à cuidadora ou ao cuidador.

Cuidar não pode simplesmente traduzir uma noção romantizada de abnegação, nem pode ocorrer se o ser permanecer à parte. Para que alguém possa cuidar de outro, é necessária uma ligação entre o ser e outro, e a natureza dessa ligação constitui um problema para qualquer ética do cuidar. (TRONTO, 1997, p. 193).

Nessa perspectiva, Eva Kittay (2011) reflete sobre o fato de que a dependência é uma condição inevitável na trajetória de vida de todas as pessoas, pois demandaremos cuidado em algum momento da vida. As interações vivenciadas, de diversas formas, nas relações sociais, evidenciam a dependência humana. Ser dependente não é exclusividade de alguma classe social da sociedade, a infância e a velhice são provas de que em algum momento de nossa vida nós precisaremos de cuidado. Portanto, o cuidar, não envolve apenas um grupo, mas é condição humana, para vivermos melhor no mundo.

O mundo em que vivemos tem a independência como norma de funcionamento humano, o que piora para as pessoas com deficiência, na medida em que para viver suas vidas elas necessitam de cuidado. O cuidado - e o cuidador - são estigmatizados pela dependência (KITTAY, 2011). A idealização de uma independência, como caminho para uma vida digna, é mera ilusão, não apenas para as pessoas com deficiência, mas para todos nós.

Os estudos sobre deficiência são permeados de tensões ao discutir sobre o cuidado, pois, a primeira geração do modelo social, grupo formado por homens com lesão medular, tinha como pauta "a independência como valor ético para a vida humana” (DINIZ, 2012, p. 57); eles defendiam que, ao serem retiradas as barreiras sociais, arquitetônicas e de transportes, as pessoas com deficiências exerceriam sua independência (DINIZ, 2012). Como podemos observar na afirmação de Oliver e Barnes:

A dependência é criada entre pessoas com deficiência, não por causa dos efeitos das limitações funcionais em suas capacidades de autocuidado, mas porque suas vidas são moldadas por uma variedade de forças econômicas, políticas e sociais que produz 
essa dependência (OLIVER; BARNES, 2012, p. 140, tradução nossa).

Dessa forma, o "cuidado ou os benefícios compensatórios para o deficiente não estavam na agenda de discussões" da primeira geração (DINIZ, 2012, p. 57). Os precursores do modelo social da deficiência procuraram entender a deficiência segundo o conceito de estigma de Goffman (2016), segundo o qual os sinais corporais prenunciam quais os papéis a serem desempenhados pelo indivíduo.

Nos anos de 1990 e 2000, as teóricas feministas da segunda geração do modelo social trouxeram novos argumentos para os estudos sobre deficiência. Elas criticaram a supervalorização da independência, pois existem pessoas que não serão capazes de vivê-la, mesmo que lhes sejam retiradas todas as barreiras (DINIZ, 2012). Medeiros e Diniz (2004) mostram que a dependência por meio do cuidado faz parte da vida em sociedade e, para muitas deficiências, não é possível evitá-la. Corroborando com o pensamento de que todos os indivíduos, com ou sem deficiência, são dependentes um dos outros, Horkheimer e Adorno (1973) entendem a sociedade

[...] como uma espécie de contextura formada entre todos os homens e na qual uns dependem dos outros, sem exceção; na qual o todo só pode subsistir em virtude da unidade das funções assumidas pelos coparticipantes, a cada um dos quais se atribui, em princípio, uma tarefa funcional; e onde todos os indivíduos, por seu turno, estão condicionados, em grande parte, pela sua participação no contexto geral (HORKHEIMER; ADORNO, 1973, p. 25).

Nesse sentido, defender a igualdade de oportunidades para todas as pessoas é grandioso, porém, existem pessoas que, mesmo retirando-se todas as barreiras na garantia de torná-las independentes e autônomas, não conseguirão desfrutar das oportunidades ofertadas. Esse é o caso das pessoas com múltiplas deficiências, como por exemplo, deficiência intelectual severa, paralisia cerebral, baixa visão, surdez, entre outras deficiências.

A opressão vivenciada por um corpo atípico foi colocada em pauta pelas teóricas feministas da segunda geração do modelo social5. Os argumentos feministas desafiaram a cultura da normalidade ao trazer para a discussão a interdependência, o cuidado e os impedimentos intelectuais. Segundo Medeiros, Barros e Neto (2010, p. 13), a "deficiência não é um conceito neutro que descreve corpos com impedimentos, mas o resultado da interação do corpo com impedimentos com ambientes, práticas e valores discriminatórios".

5 A primeira geração do modelo social era composta por homens brancos com lesão medular. As teóricas feministas trouxeram à tona temas esquecidos como a interdependência e o cuidado próprio da condição humana (DINIZ, 2012). 
A dependência é um conceito amplamente debatido e contestado, pois é visto como algo negativo. A palavra dependência, tem como significado: "estado ou qualidade de dependente; subordinação, sujeição. Disposição para a obediência; submissão à vontade de outrem. Necessidade de proteção, amparo, arrimo. Na Psicopatologia significa incapacidade de tomar decisões sozinho, o que leva a entregar as responsabilidades a um parceiro ou a outras pessoas" (HOUAISS, on-line). Dessa forma, pode-se observar que a dependência é vista como um atributo individual e embaraçoso para o domínio público. Em concordância, Fine e Glendinning (2005) afirmam que, nas democracias liberais avançadas, a compreensão da realidade da dependência é negada pela promoção de um ideal de autonomia individual.

A dependência, conforme o seu significado, também implica domínio, possessão, pertencimento. As relações de cuidado são relações de poder, "a dependência caracteriza-se pela necessidade de assistência, que pode ser atendida através da prestação de cuidados; e o cuidado pode criar ou aprofundar a dependência” (FINE; GLENDINNING, 2005, p. 6o8, tradução nossa). A pessoa com deficiência múltipla está mais vulnerável nas relações de poder com o cuidador, por causa da ausência de capacidade física e/ou intelectual. O que não significa que não exista uma relação de responsabilidade e confiança.

Já a vulnerabilidade do cuidador surge por sua posição social, a presteza em ajudar, o isolamento doméstico, a preocupação com o bem-estar do destinatário do cuidado, o abrir mão, muitas vezes, de sua vida pessoal em prol do outro e da carência de apoio no âmbito privado e público, são apenas alguns exemplos para demonstrar que, nesta relação, o cuidador pode, de algum modo, estar desamparado, necessitando de esclarecimento, aconselhamento, serviço de suporte e apoio financeiro o qual, provavelmente virá do provedor (chefe da família), de aposentadoria ou do apoio financeiro do Estado, através das políticas de transferência de renda.

As teóricas feministas da ética do cuidado enfatizam que o cuidado precisa ser visto como algo positivo de uma rede complexa de relações. Destacam, ainda, a importância do cuidado, chamando a atenção para outras variáveis, além do corpo com deficiência em experiência de opressão, tais como classe, gênero, religião, raça, idade ou orientação sexual, entre outras (MELLO; NUERNBERG, 2013). A pessoa que, geralmente, exerce o cuidado no contexto familiar, é a figura feminina, conforme relatam Diniz e Medeiros (2004):

Ao mostrar que a deficiência é acompanhada de arranjos familiares voltados para o cuidado da pessoa deficiente, essas pensadoras evidenciam que não são apenas as pessoas com algum tipo de restrição corporal que necessitam da atenção das políticas públicas. Como, devido à divisão sexual do trabalho, os cuidadores são, predominantemente, mulheres, a deficiência, quando entendida como um fenômeno familiar, possui um viés de gênero. São as mulheres, por exemplo, que se afastam do mercado de trabalho para cuidar das pessoas com deficiência, de crianças pequenas, ou de idosos (MEDEIROS; DINIZ, 2004, p. 111). 
O papel tradicional das mulheres em cuidar dos dependentes continua a ser um empecilho na luta pela igualdade. As mulheres cuidadoras de dependentes na família, frequentemente, ficam extenuadas ao enfrentar a jornada dupla de trabalho e uma total responsabilidade pelas tarefas domésticas e pelo cuidado com os filhos; com isso, perdem a chance de entretenimento e aperfeiçoamento da imaginação e da cognição (NUSSBAUN, 2010). O ônus exigido para quem exerce o trabalho de cuidador é grande, pois se espera disponibilidade a qualquer hora, principalmente se o cuidado for realizado por familiares. A necessidade e a prestação do cuidado implicam uma relação deveras desigual.

O cuidado, por não ser reconhecido como trabalho, não ocupa um lugar de destaque na economia, por isso, muitas vezes, não é pago, ou é mal remunerado e são as mulheres (mães, avós, tias, amigas) as que se ocupam desse ofício. Invertem-se os sentidos, a negação da necessidade de cuidado como condição humana reverbera na desvalorização do cuidado como trabalho. Para provocar essa mudança, é necessário aceitar que somos frágeis e que nossas relações sociais são baseadas na interdependência. Só assim, políticas públicas serão efetuadas em prol do coletivo e não do individual.

\section{Relatos maternossobrea experiência deser mulher, mãeecuidadora de uma criança com deficiência}

Em 2015, o Brasil vivenciou a epidemia do Zika vírus, fazendo com que os números de casos de crianças nascidas com deficiência múltipla com graves sequelas aumentassem abruptamente. As vidas maternas foram alteradas severamente, fato que levou a questionar como estas mães viveram a experiência da chegada da criança com deficiência na família e quais eram suas concepções sobre a deficiência. Assim, a presente pesquisa objetivou analisar experiências sobre o cuidar, relatadas por mães de pessoas com deficiência múltipla.

Para alcançar o objetivo proposto, elegeram-se, como sujeitos da pesquisa, mães que, possivelmente, durante a gestação, foram infectadas pelo Zika vírus e conceberam filhos com múltiplas deficiências. Para localizá-las, entrou-se em contato com a Secretaria de Saúde de um município do sul da Bahia, a qual nos direcionou a uma instituição de atendimento de saúde pública. Participaram da pesquisa o8 (oito) mães com idade entre 22 a 34 anos, todas não trabalhavam para cuidar do filho, sendo sete 07 (sete) delas dependentes do BPC - Benefício de Prestação Continuada, portanto, mulheres pobres que exercem a atividade do cuidado diariamente.

A coleta de dados ocorreu entre os meses de setembro e outubro do ano de 2018. Foram aplicados um questionário socioeconômico e realizadas entrevistas com oito mães. Todas as participantes, no instante da entrevista, leram e assinaram o Termo de Consentimento Livre e Esclarecido - TCLE. Foi preservada a identidade dos 
sujeitos bem como a dos seus filhos e/ou outros indivíduos citados nas narrativas. As entrevistas foram gravadas e depois transcritas fielmente ${ }^{6}$.

\section{A maternagem por tempo integral e indefinido}

A família ainda é o principal agente de socialização e é por meio dela que são construídas as relações de cuidado entre seus integrantes. É na família que o bebê terá os primeiros vínculos de afeto, sendo a figura materna a que promoverá um possível laço afetivo da criança com o pai e com as pessoas que fazem parte da estrutura familiar.

O diagnóstico trouxe para a maternidade e a maternagem inúmeros significados, e a confirmação de que o bebê foi infectado pela SCZ (Síndrome congênita do Zika vírus) originou nas mães sentimentos e perspectivas negativas, mesmo para aquelas que aceitaram a notícia de imediato. A nova realidade da família pode causar um impacto tão grande que é capaz de comprometer o estabelecimento do vínculo, a aceitação do(a) filho(a) e a assimilação do diagnóstico, como podemos observar nas respostas abaixo:

Quando a médica foi me dar a notícia, ela falou que minha filha não ia ter muito tempo de vida. Então, foi pior para mim, não é? Porque, as palavras que ela diz, que ela falou, que ela... eu assim, eu já não sabia o que era microcefalia, gerar uma criança nove meses, não é? E uma médica dizer isso... um absurdo desses... que ela não ia nem andar, não ia falar e não ia ter muito tempo de vida, então, foi um baque para mim (ANA, grifo nosso).

Ana considera paradoxal o diagnóstico, para ela não parece ser possível gestar uma criança durante nove meses e ela não andar, falar e ter pouco tempo de vida. A falta de informação ou compreensão sobre a SCZ e suas sequelas, uma vez que a médica não explicou o que era microcefalia e suas consequências, pode criar expectativas diversas. A mãe pode imaginar que a criança não terá o seu desenvolvimento afetado ou será totalmente comprometido. De uma forma ou de outra, a criança poderá ser prejudicada, pois podem presumir que ela não necessita de tratamento. Por não compreenderem a patologia, as mães, possivelmente, não saberão como nortear suas atitudes.

Vejamos os relatos de Ana e Isabel:

Na verdade, eu estou meio perdida e desligada a respeito disso, não é? Porque, assim, ela ia para atendimento em um

6 A pesquisa de dissertação de mestrado foi aprovada pelo Comitê de Ética e Pesquisa (CEP) da Universidade do Estado da Bahia (UNEB), no dia 24/o8/2018, sob o número de parecer 2.841.365. 
hospital em Salvador, então eles me falavam a respeito dela, não é? O probleminha dela, mas só que eu ainda não entendi o... a deficiência dela (ANA, grifo nosso).

[...] a médica não me deu certeza, me deu os exames para fazer para eu ter aquela certeza. Ela falou: Mãe, realmente seu filho...o tamanho da cabeça do seu filho está abaixo da linha vermelha para idade dele... então, aquilo ali já dá uma preocupação, já é um choque, não é? Mas, ela também não afirmou nada, foi com os exames que eu fiz, mostrei para a doutora que diagnosticou o que Igor realmente tinha (ISABEL, grifo nosso).

A partir do relato de Isabel, pode-se observar que a noção de desenvolvimento aqui esperada é a definida pela biologia evolutiva e seguida pelo discurso biomédico na prática clínica, portanto, os bebês infectados pela SCZ que não acompanham a curva do desenvolvimento infantil são caracterizados como anormais, atrasados e abaixo do desenvolvimento esperado.

Por outro lado, o desenvolvimento da criança acometida com deficiência múltipla em consequência da SCZ é incerto. Assim, a forma como a notícia é assimilada pela família poderá abalar o vínculo a ser desenvolvido entre a mãe e a criança, afetando a maternagem, ou seja, o afeto, o cuidado e o carinho poderão ser comprometidos.

Considerando as informações acima, perguntou-se às mães se elas buscaram acompanhamento para elas após a comunicação do diagnóstico e todas afirmaram que não, só para os filhos.

Não, na verdade meu marido até teve um colega que a mãe é psicóloga, ela até ofereceu, mas assim, eu nunca senti necessidade. Porque também eu não fiquei depressiva... tive aquele momento de luto normal, não é? Um período fiquei triste, mas para mim foi algo que passou logo, porque eu pensei assim: não adianta ficar triste porque minha tristeza não vai mudar as coisas e ele precisava de mim, precisa, não é? Então, eu falei: não vou entrar em uma depressão agora e uma tristeza porque isso não muda nada. Eu pensei, tenho que levantar e lutar por ele, foi o que eu fiz... até hoje (TERESA, grifo nosso).

O relato de Teresa demonstra o cuidado nas relações, independentemente dos conflitos emocionais por ela sentidos, ela não se permite mostrar-se vulnerável, coloca de lado os sentimentos gerados pela perda do filho idealizado para cuidar do filho real. Amaral (1995) aponta que "frente ao nascimento de uma criança com deficiência o estado psíquico vivido pela família é de perda, morte mesmo”, e acrescenta que é preciso vivenciar o luto pelo filho "perdido", para, então, receber o filho real (AMARAL, 1995, p. 78). Já Isabel, que descobriu tardiamente a deficiência do filho, esperava que a instituição oferecesse atendimento. 
Eu não busquei, porque lá quando eu passei pela instituição, eles falaram que nós teríamos... passaríamos por psicólogo... essas coisas... porque... pra gente é um choque, não é? É um baque a gente aceitar, mas... se eu já amo meus filhos, eu acho que é dobrado, o carinho e o cuidado, não é? Eu... às vezes falta paciência, sim! Falta sim, porque... hoje eu estou vivendo para ele (ISABEL, grifo nosso).

Os discursos de Isabel e Teresa desvelam que as reações emocionais necessitam ser cuidadas, pois ao negarem seus sentimentos reais, impedem que as emoções geradas pela deficiência do filho sejam resolvidas adequadamente. $\mathrm{O}$ enfrentamento dos sentimentos irá direcionar a afetividade para o filho real e não ao objeto de fantasias, podendo desfazer-se dos laços com o filho perdido. A esse respeito, Marques destaca:

Por detrás de uma fachada de tranquilidade ou ferocidade, as mães sempre estão habitadas pela angústia. Todavia, sua habilidade consiste em negá-la, sendo que a recusa de saber constitui uma prova de saúde. Esta angústia é por elas situada na relação com o outro, preocupando-se com o que o outro espera ou pode suportar delas (MARQUES, 1988, p. 124).

As mães deste estudo, apesar de sofrerem com o diagnóstico, não se permitiram vivenciar os sentimentos de perda, pois elas deviam demonstrar força para suportar todas as adversidades. As identidades femininas são constituídas em cima de discursos culturais sobre os significados de a maternidade ideal estar associada ao amor e ao cuidado, sendo criada a imagem de uma "boa" mãe, ou seja, aquela capaz de abdicar da sua vida em benefício do filho, do bom cuidar. A respeito disso, Helena e Clara afirmam, respectivamente:

Antes eu pegava minha filha de cinco anos, que era menor, os outros e íamos para a praia no final de semana, íamos para casa de parente e para casa de amigos. Depois que ele nasceu... cortei essas atividades. Hoje é mais ou menos assim: às vezes, eu pego ele e a de cinco anos e a gente vai para a praia, mas ele não pode estar tomando sol, coloco ele na água e na mesma da hora ele já está... começa a tossir demais, já fica agoniado, tem muito barulho ele já fica muito nervoso, agitado, por causa do refluxo, a maioria... [...] O povo fica naquela... antes eu parava em um lugar e tomava uma cervejinha, agora... se eu tomar uma cerveja é dentro de casa, porque na rua... se eu sentar em qualquer... no bar... eu não vou para porta de bar com ele, mas mesmo que eu esteja entre amigos, todo mundo junto... eu já procuro evitar. Tem muita gente que passa por fora e não conhece, já fica questionando (HELENA, grifo nosso). 
[...] que bom que pelo menos as pessoas reconhecem, não é? Reconhece o que eu faço... porque tem mãe... que misericórdia... só tem o nome de mãe (CLARA, grifo nosso).

As estratégias de dominação perpetuadas pela sociedade patriarcal fazem com que a mulher/mãe se auto vigie e seja vigiada, sendo cobrada e cobrando aquilo que ela sabe que não consegue ter, a perfeição. Sendo assim, Helena deixa de frequentar alguns lugares para evitar o sofrimento de ser lembrada que tem um filho com deficiência. Paradoxalmente, a mãe sofre com a vigilância constante, pois sentese incomodada com a curiosidade, os olhares, os comentários e a rejeição das pessoas, ao mesmo tempo que espera o reconhecimento por ser uma boa mãe/cuidadora. De acordo com Badinter (1985), não é o amor que leva as mulheres a cumprir com seus deveres maternais, mas sim os valores morais, sociais ou religiosos.

Para Gilligan (1982), o cuidado está relacionado à ética e à moral, não apenas ao desejo ou ao querer cuidar, mas ao dever autônomo que envolve campos afetivos e da razão. Dessa forma, a mulher priva-se de seus desejos e sentimentos, optando por manter a "conexão humana", que Gilligan (1982, p. 41) define como "o reconhecimento da responsabilidade de uns pelos outros". Sendo assim, independentemente do que estas mães/mulheres sentem, elas cuidarão dos seus filhos. Seguem as narrativas maternas sobre o que pensaram após a confirmação do diagnóstico:

Ah! Sei que tem umas mães que não se conformam, não é? Que fica e tudo, não é? Mas depois a gente se conforma... por que no caso tem que cuidar, não é? (CLARA, grifo nosso).

Pensei que ele não ia andar, não vai falar, que ele não vai fazer nada (ri), que seria dependente de mim o resto da vida, eu pensei logo. Pronto, não vai fazer nada. E que eu ia ficar presa a isso, o resto da vida, eu falei pronto a minha vida está presa a ele, assim, para o resto da vida, dedicação a ele para o resto da vida. Tipo, trabalho para mim não ia existir mais, passeio, essas coisas assim, fazer outro tipo de atividade para mim, na minha... seria impossível, porque é dedicação a ele para o resto da vida (TERESA, grifo nosso).

Eu pensei que eu tinha que parar a minha vida, não é? Que eu tinha que sair do trabalho para eu viver para ela e não pra mim, então, é hoje o que eu faço, eu vivo por ela, eu não vivo por mim (ANA, grifo nosso).

As narrativas apresentadas denunciam o cuidado como atribuição feminina e como um trabalho solitário. Essas mulheres não abandonaram apenas o trabalho, colocaram de lado seus projetos, sonhos, estudos, desejos, ou seja, vão viver a vida apenas satisfazendo as necessidades de outra pessoa. 
O comportamento materno ratifica a ética do cuidado pensada por Gilligan (1982), segundo a qual a moralidade reflete o entendimento das relações sociais e a responsabilidade é considerada segundo uma moral feminina. Para a autora, isto significa priorizar o outro, ou seja, fazer o que tem que ser feito independentemente do que se queira, indo para além do princípio da justiça, visando à manutenção dos relacionamentos. No entanto, a autora alerta que esta ética não deve servir de sustentação para a estrutura patriarcal, longe disso, deve favorecer a inserção nas mais diversas entidades, as possibilidades de diálogos serão ampliadas favorecendo um maior amadurecimento moral entre os gêneros (GILLIGAN, 1982).

As teorias morais que regem a sociedade estão baseadas em vozes masculinas, isso significa que a dignidade humana está atrelada à capacidade de autonomia e independência. Gilligan (1982) e Noddings (2003) realizaram duras críticas a esta ética, pois entendem que são baseadas em princípios masculinos, visando os direitos individuais, a integridade e a justiça. O cuidado com as relações humanas, considerado uma linguagem feminina, foi silenciado nesse processo. Apesar de as autoras concordarem neste ponto, elas divergem quanto à abordagem moral, pois Gilligan (1982) não favorece a ética do cuidado em detrimento da ética de princípios e de direitos; para a autora elas se complementam, diferentemente de Noddings (2003).

Isto posto, é preciso problematizar sobre a falta de políticas públicas direcionadas para cuidadores de pessoas com graves restrições cognitivas, intelectuais e motoras cuja sobrevivência depende de cuidados fornecidos por outra pessoa, tendo sido esse cuidado naturalizado como materno. É preciso existir complementariedade entre as teorias do cuidado e a da justiça, pois o cuidado não é entendido como uma questão de justiça.

Em sociedades que não reconhecem a dependência, frequentemente a pessoa que cuida é explorada e invisibilizada. O trabalho do cuidado ocupa uma posição inferior em uma hierarquia de gênero que organiza a vida em sociedade, por isso não há políticas públicas voltadas ao cuidado, tampouco proteção social para quem o exerce. A questão da deficiência compreendida sem a abordagem transversal de gênero produz impactos significativos na vida de pessoas que exercem diariamente o ofício do cuidado (GUIMARÃES, 2010, p. 208).

Sobre qual o papel de cada familiar no cuidado para com o filho, as mães responderam que não existiam papéis, as pessoas ajudavam, mas não se responsabilizavam com o cuidado. Seguem os relatos:

Todo mundo me ajuda de uma forma, mas eu acho que o papel maior mesmo é o meu de mãe, entendeu? Se eu precisar que minha mãe fique com ela, ela fica, minha irmã também fica, mas ali mesmo, quem na batalha no dia a dia dela sou eu (MARIA, grifo nosso). 
Só se for minha filha de 20 anos que já se casou. Se ela puder, se for um dia que ela não tiver um curso, ou alguma coisa, ela ainda olha, mas a não ser mais ninguém (HELENA, grifo nosso).

Os relatos de Maria e Helena demonstram que o cuidado é, geralmente, exercido por mulheres, sejam mães, irmãs, filhas, avós; logo, cuidar de alguém está limitado/circunscrito à questão de gênero, pois ainda é entendido a partir de uma ética feminina, um trabalho realizado por amor e não uma prática aprendida culturalmente (NODDINGS, 2003). Assim, as pessoas cuidariam de outras porque as amam e as consideram importantes.

O cuidado com crianças com microcefalia é uma tarefa extensa, requer atenção às características individuais, pois muitas apresentam crises convulsivas, refluxos crônicos, choro ininterrupto e as mães aprendem a reconhecer e administrar os momentos de crise. Ao serem perguntadas sobre a rotina diária, Débora e Isabel responderam:

Corrida, muito corrida. Aqui a vida é corrida, muito corrida. Antes era o tempo todo em médico com ele, porque ele estava dando as crises, ia e voltava, eu levava para a doutora... A doutora atendia no hospital, mas agora não atende mais. Na época quando ele logo adoeceu, quando ele dava as crises era assim, ia e voltava, ia e voltava, ia e voltava. Até hoje, atrás de receita, passa um remédio caro, passa três frascos, ele usa três frascos por mês. Eu não vou ter condições de comprar três frascos tudo de uma de vez só, não é? Ela coloca três para comprar, daí é corrido., muito corrido (DÉBORA, grifo nosso).

Minha rotina é cuidar de meu filho dentro de casa, fazer as coisas mesmo, levá-lo para a instituição para atendimento médico, porque ele tem a imunidade muito baixa, então tem que estar sempre fazendo consultas médicas, essa é minha rotina. (ISABEL, grifo nosso).

O cotidiano materno é intenso, com a rotina de cuidados e agenda médica, suas tarefas são solitárias, o silêncio no discurso materno quanto ao papel paterno na rotina diária demonstra que ele não participa do cuidado para com os filhos. Dessa forma, as mães são as únicas cuidadoras, vivenciando uma rotina de cuidados para com o outro.

Ressalte-se que essa condição, provavelmente, não se aplica a todas as mulheres, e sim às que possuem baixa renda e menor escolaridade. As mulheres em situação financeira mais confortável têm maior probabilidade de conseguir melhor atendimento, alimentação, lazer, ajuda profissional de saúde física e mental, melhores condições de transporte e casas. Portanto, não há dúvida de que o cuidado é mais bem oferecido a pessoas com maior renda e não dependem do poder público. 
As vidas maternas desta pesquisa foram alteradas devido à demanda de cuidado exigida pela criança com deficiência, mas, principalmente, pela baixa renda familiar per capita, já que 87,5\% das mulheres entrevistadas sobrevivem com apenas um salário mínimo proveniente do Benefício de Prestação Continuada (BPC)7. Logo, a deficiência cobra um alto preço às mulheres/cuidadoras economicamente vulneráveis e com baixa escolaridade.

Nessa perspectiva, a mãe/cuidadora acaba por se isolar do contato social e do lazer, diminuindo a sua socialização, pois a dedicação com o filho é tão árdua que ela se abandona e é abandonada. Quando questionadas sobre como eram suas vidas antes da criança com deficiência nascer e como ficaram depois do nascimento, as mães relataram:

A minha vida acho que [entonação triste] ... antes eu trabalhava, agora não posso mais trabalhar por causa dela, não é? Para sair de casa e deixar ela, não posso. Eu acho que teve coisas em minha vida que eu parei. Eu parei de sair [pausa longa] ... logo no começo, não é? Não saía muito, mas agora não, agora eu saio mais... (JOANA, grifo nosso).

Bem, quando ela nasceu... antes dela nascer eu era uma adolescente, eu gostava de ir à praia, eu gostava de ir para o sarau, eu tinha minha vida livre (MARIA, grifo nosso).

A pesquisadora interrompe a entrevista e pergunta se ela trabalhava antes da filha nascer:

Trabalhava, antes dela nascer eu trabalhava, depois que ela nasceu, eu tive que abdicar do meu emprego para cuidar dela e minha rotina... 90\% é em torno dela (MARIA, grifo nosso).

As narrativas maternas demonstram que a rotina de cuidados é tão intensa que acaba por isolá-las socialmente, pois o seu tempo é direcionado para a tarefa do cuidar. De acordo com Badinter (1985), a solidão e o desamparo das mulheres estão relacionados com os ideais sociais de que a mulher é a única capaz de atender as necessidades infantis, produzindo uma carga ou sobrecarga de trabalho para a mãe.

Nesse contexto, por não existir divisão de tarefas na atividade do cuidado, a maternagem cobra um alto preço, pois como cuidadoras únicas, Joana e Maria não conseguem conciliar seus desejos pessoais, como, por exemplo, o trabalho remunerado, com o ato de cuidarem das filhas com deficiências. A vulnerabilidade social das famílias é um dos motivos, pois a baixa escolaridade das mães não

7 O BPC éum benefício individualizado de transferência regular de renda no valor de um salário mínimo, independente de contribuições anteriores, não podendo o beneficiário, conforme A Lei no 8.742/1993, art. 20, $\S 4^{\circ}$, acumular o benefício com outro qualquer, seja no âmbito da seguridade social ou de outro regime, salvo os da assistência médica e da pensão especial de natureza indenizatória (BRASIL, 1993). 
oportuniza condições salariais adequadas para contratar um(a) cuidador(a) formal. Sendo assim, as mães saem do trabalho, não por opção, mas por necessidade.

Esses dias, a médica falou, se você conseguisse... ela falou assim: É, as coisas com seu filho estão ficando difíceis, a situação... sem você ter outra renda e tal, seria bom se você conseguisse um trabalho e fosse trabalhar... eu falei assim: Sim! E ele? Pagar uma pessoa que fosse responsável para tomar conta? Eu falei: é... aí essa pessoa vai me cobrar o valor do salário dele, para olhar ele, então, vai dar no mesmo praticamente (HELENA, grifo nosso).

Eu estava desempregada, não é? [...] E aí eu estou nessa luta... Deus concedeu o benefício para Igor para poder a gente viver... (ISABEL, grifo nosso).

O BPC é visto pelas mães como salário, a política assistencial que deveria ser um direito individual foi convertida em renda familiar. Tem direito ao BPC a pessoa com deficiência e o idoso que vivem em situação de miserabilidade, com rendimentos familiares menores que $1 / 4$ do salário mínimo. Ou seja, para o Estado a deficiência é um problema familiar, a partir do momento em que a família não é capaz de garantir a sobrevivência da pessoa com deficiência, o Estado assume.

No caso das crianças com deficiência múltipla com graves sequelas, o cuidado diário é essencial para mantê-las vivas, as mulheres necessitam sair do trabalho e, provavelmente, não voltarão, pois a demanda por cuidado é intensa. Ao ficar desempregada, dois problemas mais imediatos podem surgir: o primeiro é que essa família, provavelmente, não conseguirá sair da situação de extrema pobreza; e o segundo é que, se o filho falecer, essas mulheres estarão desprotegidas pela previdência social e terão dificuldades para adentrarem ao mundo do trabalho, por estarem fora do mercado há muitos anos.

A dependência do BPC não foi uma escolha para estas mães, as narrativas de Joana, Maria e Helena, demonstram o quanto sentem falta do trabalho remunerado. Essa dependência pode gerar relações opressivas, pois a criança não tem autonomia e suas necessidades serão determinadas pela cuidadora, esse vínculo pode tornar-se uma relação de autoridade, acabando por ser desigual.

$\mathrm{Na}$ instituição, eu tenho neuropediatra, assistente social, eu tenho nutricionista, técnico operacional, fonoaudióloga, tem tudo. [...] Lá a gente só pode... durante o tratamento, enquanto a gente estiver... só tem direito a duas falta e a gente tem que estar sempre justificando se precisar faltar algum dia (ISABEL, grifo nosso).

Isabel demonstra em seu relato que as necessidades cotidianas do filho se tornaram suas, a vida materna passa a orbitar em torno da criança como se fossem 
apenas uma. Ao mesmo tempo, a relação pode se configurar como uma relação de poder, a criança é levada a lugares que a mãe acha conveniente. Apesar de as terapias serem necessárias para uma melhor qualidade de vida da criança e da família, as mães, em nenhum momento, expressaram as vontades infantis, as mães decidem por eles.

Isso também foi observado quando perguntadas sobre o papel familiar no cuidado: apesar de serem ajudadas, as mães confessam que não confiam em deixar a criança com outro familiar.

\section{[...] eu nunca confiei em deixar com outra pessoa (TERESA).}

Inclusive eu só saio aqui para cuidar das coisas dele, assim para poder eu sair para um lugar... eu sair e deixar ele, não (CLARA, grifo nosso).

No entanto, Helena demonstra a dificuldade de encontrar suporte:

Ninguém nunca quis assim, nunca se impôs [...] eu falei assim: nunca mais eu saí [...] minha sobrinha falou, eu tenho medo de cuidar dele, ele, de dá comida a ele. Porque para dar comida a ele, você tem que espremer um pouquinho para ele engolir e aí ele coloca tudo para fora, aí volta tudo de novo o processo. Eu morro de medo desse menino dá uma crise dessas e eu não saber o que fazer, aí fica naquilo, ninguém se responsabiliza e diz: eu vou cuidar dele hoje para você... (HELENA, grifo nosso).

As complicações neurológicas são um grande empecilho para encontrar uma ajuda para o ato de cuidar, justificando, portanto, a insegurança em deixar as crianças com outro cuidador. Assim, foi percebido nessa análise, que, apesar de a mulher estar ressignificando o seu papel na sociedade, criando estratégias, assumindo novos papéis, alcançando postos antes negados, o cuidado ainda é um trabalho feminino, sustentado pela hegemonia do pensamento patriarcal. A análise demonstrou que a mãe/cuidadora esquece de si, assumindo toda a responsabilidade no cuidado para com o filho com deficiência, acabando por criar uma dependência mútua entre o binômio mãe/filho intensificando o afeto e o laço na relação.

\section{Cuidar: o cotidiano materno}

A experiência de ser mãe de uma criança com deficiência é construída gradativamente, durante o processo de maternidade e maternagem. Benjamim (1994) afirma que, com o desenvolvimento da técnica a modernidade tornou-se pobre em experiência, pois os bens culturais que poderiam nos conduzir a uma experiência, 
nos foram subtraídas. Assim, a pobreza se converteu não só em uma carência em experiências privadas, mas também em experiências da humanidade. Apesar disso, foi possível observar a experiência materna construída através do cuidado para com a criança com deficiência:

O que eu pensei? No momento, eu fiquei com muito medo, não é? De não conseguir cuidar dela, mas com o tempo, a gente vai aprendendo, vai conversando com outras mães e vai adquirindo mais conhecimento, vai pesquisando também, olhando na internet né? E aí vai cuidando (JOANA, grifo nosso).

Não, porque eu vim aprender mesmo com o dia a dia, entendeu? Com minha rotina, passando por vários profissionais, assim que eu fui entendendo. Mas à primeira vista, assim que ela nasceu, a médica não me explicou que eu teria todo esse processo de trazer ela para fisioterapia, para a fonoaudiologia... eu achei que... na verdade a falta de experiência na minha casa por não conviver, nunca tinha convivido com pessoas assim, nem eu e nem meus familiares, a gente... eu pensei que ela fosse se desenvolver normal, entendeu? Ela nasceu com problemas, mas ela iria falar, ela iria andar com facilidade, não sabia que tinha que fazer todo esse processo de trazê-la para profissionais de áreas diferentes, como a fonoaudióloga, a fisioterapeuta, a musicoterapia que ela faz também (MARIA, grifo nosso).

O tempo para Joana e Maria foi essencial para aceitar a realidade, adquirir conhecimento edesconstruiras expectativas na procura deressignificar a maternagem. Compartilhar as experiências vividas permite uma troca de conhecimento, uma parceria para enfrentar um destino comum. O saber da experiência ocorre num encontro único entre o sujeito e o acontecimento. De acordo com Larrosa (2018, p. 25), "o sujeito da experiência é sobretudo um espaço onde têm lugar os acontecimentos". As mães entrevistadas tiveram um acontecimento comum, filhos(as) com múltiplas deficiências, todavia, a experiência foi singular para cada uma. Portanto, a experiência não pode ser ensinada, sendo da ordem dos afetos.

De acordo com Larrosa (2018), o sujeito da experiência é aquele que permite a experiência dele se apoderar. Portanto, é preciso estar aberto a empreender a sua própria transformação, como foi realizado por estas mulheres. Segue os relatos maternos:

Assim, minha vida mudou totalmente [...] é, porque tipo assim, eu não tenho outra rotina porque tudo que eu fizer eu tenho que estar com ele, porque eu não tenho com quem deixar [...] (ISABEL, grifo nosso). 
Meu pensamento era de dar todo apoio, não é? Porque ele não pediu para vir assim, então, meu pensamento é oferecer apoio até o resto da minha vida e da dele. (DÉBORA, grifo nosso).

Ah! Foi correria, porque hoje eu vivo para isso, para levar ele aos tratamentos, para cuidar dele, hoje eu vivo basicamente para isso. Levar ele para as terapias, cuidar dele e o lazer dele que a gente também não abre mão, levar ele para passear, brincar, essas coisas (TERESA, grifo nosso).

Ali eu percebi que ia mudar tudo, não é? Não tinha negócio de estar saindo mais, era cuidar dele. O cuidado dobrado do que tive com os outros, o amor em dobro, tudo em triplo assim ou em dobro (HELENA, grifo nosso).

Isabel, Débora, Teresa e Helena modificaram suas vidas em prol dos(as) filho(as), a experiência da maternagem as transformou, alterando o curso de suas vidas. Segundo Kittay (2011), nas relações de cuidado as partes envolvidas coexistem, estão estritamente ligadas, afetando e sendo afetadas.

A experiência em lidar com a condição de cada criança é distinta, as mães personalizam o cuidado, a depender da necessidade infantil. Ao conhecer intimamente o(a) filho(a), as mães/cuidadoras sabem quais cuidados são necessários; contraditoriamente, o cuidado se torna automático. Seguem as rotinas de Teresa e Maria:

Da hora que acorda até a hora de dormir? O básico... Ele acorda pela manhã, eu faço a vitamina dele, aí faço meu café e o do meu marido. Vou cuidar dele, escovar dente, trocar fralda, banho, essas coisas, ele vai ver televisão enquanto eu vou fazer as coisas da casa, ajeitar, fazer almoço e tal, brinco com ele e meio dia... meio dia ele almoça, dorme tira o cochilo (não é mãe?), lancha à tarde, à noite toma o cafezinho dele, brinca. E nos dias entra os horários das terapias, menos quarta-feira que eu disse que não ia colocar nada. É o dia... porque eles ficam muito sobrecarregados também (TERESA, grifo nosso).

Pela manhã, eu sempre acordo primeiro que eles, preparo o café, quando eles acordam, eu dou a mamadeira para meu filho, ele toma sozinho e dou o café dele. Depois, banho, aí eu vou preparar o almoço, limpar a casa, às dez horas mais ou menos um lanchinho para eles, sempre uma fruta, uma vitamina, alguma coisa. Depois, meio dia, uma hora mais ou menos, vem o almoço. À tarde, novamente, eu tenho um cachorrinho, vou limpar a casa de novo por causa das crianças, umas três horas o lanche deles novamente. Na segunda-feira, 15 horas a gente vai para a musicoterapia e à noite vêm a janta, depois outro lanche, porque meus filhos comem, comem mesmo, depois eles vão dormir, entre 
dez horas mais ou menos, eles vão dormir. Na terça-feira, pela manhã, a gente se levanta e vem para a instituição de saúde, aí quando a gente chega em casa ela vai tomar banho, já não tem mais lanche porque a gente chega em casa tarde, já vai para o almoço. Eu vou preparar o almoço, ela vai almoçar e aí a rotina normal à tarde. Na quarta-feira a mesma coisa, viemos para aqui, a mesma rotina. Na quinta-feira a mesma rotina, a gente para aqui novamente e quando chega em casa, aquela mesma coisa, eu vou preparar o almoço porque eles comem comida fresquinha, eles não comem coisas geladas e aí... Sexta-feira a gente volta para a rotina de segunda-feira tirando a música. [E lazer?] Às vezes a gente vai à praia, à praça no sarau, a missa aos sábados, depois vamos ao sarau (MARIA, grifo nosso).

As falas de Teresa e Maria demonstram que a relação com a criança vai sendo construída no processo de convivência, a vida cotidiana permite que tenham consciência das necessidades dos(as) filhos(as). Porém, demonstraram que, ao conhecer o outro profundamente, o cuidado, que é a ação entre quem cuida e quem o recebe, tornou-se automático. O pensamento e a ação tornaram-se pragmáticos; como argumenta Heller, citada por Patto (2008), não é possível refletir sobre todo o conteúdo relacionado a nossa vida comum, sem essas adaptações não haveria sobrevivência.

Nesse contexto, as mães, de forma particular, adaptam-se à vida cotidiana com o intento de garantir a sua sobrevivência e sua função social. Logo, efetuam o cuidado de forma automática, que é uma das mais diversas formas pelas quais os indivíduos desempenham atividades de autoconservação. Neste caso, as mães/ cuidadoras se adaptaram à rotina diária como forma de sobrevivência, a criança necessita de terapias para ganhar o máximo de autonomia possível e elas terem as atividades de cuidados amenizadas.

No início foi um pouco difícil, porque eu trabalhava e eu tinha que me adaptar, a trabalhar [...] foi bem difícil mesmo, eu fui me adaptando aos poucos (MARIA, grifo nosso).

A minha família... todo o mundo me apoiou. [E seu esposo quando descobriu?] Ficou... no caso, não é? No começo a pessoa tem um choquezinho, mas depois a reação foi normal (JOANA, grifo nosso).

Minha família também não sabia o que era microcefalia, a gente pensou que era coisa de médico mesmo, porque assim, na família dele não tem ninguém, na família minha também não, então a gente ficou assim que nem uma balança, não é? Sem saber (ANA, grifo nosso). 
Maria, Joana e Ana demonstram que foi necessário um tempo para a adaptação. A relação dos indivíduos com o meio em que vivem é de modo simultâneo o meio natural e a sociedade, e ocorre com a finalidade de garantir a autoconservação, portanto, compete assegurá-la a todo custo considerando o meio em que estão inseridas. Assim, a mãe, com o intuito de preservar a si mesma e ser capaz de sobreviver na ordem social vigente, adapta-se de tal maneira a ela e aos fins já estabelecidos que sua própria individualidade é ameaçada. Dessa forma, o trabalho de cuidar envolve, simultaneamente, trabalho emocional e técnico.

Horkheimer (2015) alerta que a promessa de individuação, nesta sociedade, foi interrompida e a vida individual está reduzida à necessidade de adaptação à ordem existente. Com base na teoria crítica de Horkheimer, Cook resume:

Paradoxalmente, a autoconservação determina a conformidade com uma sociedade que mina todas as tentativas de preservar qualquer vestígio de individualidade autônoma. Para preservar a si mesmo, é preciso adaptar-se a modelos de comportamento socialmente aprovados (geralmente fornecidos pela indústria cultural), bem como às ofertas predominantes de satisfação de necessidades, nas quais as diferenças reais entre si e os outros são suprimidas. A conformidade com o status quo parece ser a única linha de conduta disponível hoje. (COOK, 2004, p 47, tradução nossa).

Nesse contexto, as mães cuidadoras procuram atender as expectativas de cuidado colocadas pela sociedade e por si mesmas. Submetem-se a um conjunto de regras sociais já estabelecidas, as quais custam a sua própria individualidade. Por outro lado, como não existe nenhum apoio familiar e governamental para que essas mães tenham ao menos um dia livre, elas não têm escolhas, precisam atender as regras para sobreviverem. Quem cuida sofre opressão, pois a família tornou-se "mediadora de uma racionalidade autoconservadora, endurecida e incapaz de refletir e se opor ao que a oprime" (MOURA, 2011, p. 63).

Assim, a autoconservação, da qual o produto contemporâneo é a adaptação, poderia já ter sido superada com o uso da razão para denunciar as diversas formas de injustiça e delas emancipar-se. Por outro lado, o cuidado realizado por essas mulheres/mães/cuidadoras não é só adaptação, é resistência, pois vai na contramão de uma sociedade que proclama a independência e a autonomia.

Adorno e Horkheimer (2006) compreendem que a razão se tornou instrumental: a capacidade humana cujo objetivo é a garantia da autoconservação da espécie humana através da dominação da natureza e da conformação das relações entre os próprios humanos. Portanto, a história da civilização vem progredindo, de diferentes formas, com o intuito de garantir este fim último, a autoconservação da espécie e não a emancipação. 


\section{Considerações finais}

A despeito de estarmos no século XXI, são as mulheres entrevistadas que lidam com o trabalho no lar e com o filho, sozinhas. O cuidado diário, o deslocamento entre clínicas especializadas, a luta contra os estigmas e preconceitos vivenciados cotidianamente e as dificuldades econômicas, foram narradas por elas. Foi possível observar que a vida destas mulheres sofreu mudanças intensas após o nascimento do filho, pois foi necessário abdicar dos seus projetos pessoais e viver só para o filho, como dito por Ana, Teresa e Isabel.

Quem necessita de cuidados e quem cuida, em uma sociedade capitalista, que prima pela independência e volta-se para a produção, é inferiorizado e oprimido. Nesse contexto, a concepção de cuidado como justiça social só será alterada quando a compreensão da moral e do indivíduo se diferençar da definição tradicional do ser humano nesta sociedade. Isto é, enquanto o valor pessoal for medido pela lesão, cor, opção sexual, religião, raça ou poder econômico, a sociedade obliterará a visão do todo e não oportunizará a justiça social.

Além disso, o cuidado ainda é naturalizado como obrigação feminina. As mulheres que assumem o cuidado das pessoas com deficiência ou idosos, por exemplo, tornam-se dependentes e vulneráveis, o que evidencia a desigualdade de direitos. É preciso recusar as divisões tradicionais de gênero, em uma sociedade que desvaloriza o trabalho exercido pelas mulheres e tornar o cuidado o mais democrático possível. Sendo assim, salienta-se que são necessárias políticas públicas que alcancem as famílias, principalmente as mães, pois a tarefa de cuidar as tornam invisíveis.

A ética do cuidado defende que as relações afetivas tenham mais valor que a razão capitalista, só assim, a interdependência será reconhecida como algo intrínseco ao ser humano. Para demonstrar que todos, com e sem deficiência, vivemos em interdependência, Diniz (2012) cita a provocação da filósofa e cuidadora Eva Kittay, "todos somos filhos de uma mãe", o que significa dizer que todos necessitamos de cuidados em algum momento de nossas vidas.

Por fim, cabe mencionar que enquanto não houver políticas públicas que orientem as mães o mais precocemente possível, sobre as propostas de inclusão da pessoa com deficiência, vão continuar a existir instituições especializadas, manicômios, prisões ou a segregação realizada dentro do próprio lar como sinônimos de proteção. Diante do exposto, espera-se que este estudo contribua para a reflexão sobre como os contextos sociais influenciam na inserção da família e da pessoa com deficiência nos espaços comuns, seja a escola, o shopping, a praia, o ônibus, o trabalho, os hospitais, entre outros. 


\section{Referências}

ADORNO, Theodor Wiesengrund (2009). Dialética negativa. Rio de Janeiro: Jorge Zahar Ed.

AMARAL, Lígia Amaral. (1995). Conhecendo a deficiência em companhia de Hércules. São Paulo: Robe Editorial.

ARENDT, Hannah. A condição humana. (2016). Tradução Roberto Raposo. 13. ed. rev. Rio de Janeiro: Forense Universitária.

BADINTER, Elisabeth. (1985). Um amor conquistado: o mito do amor materno. Tradução Waltensir Dutra. Rio de Janeiro: Editora Nova Fronteira.

BENJAMIN, Walter. Sobre alguns temas em Baudelaire. (1994). In: Charles Baudelaire: um lírico no auge do capitalismo - (Obras escolhidas v.3). Trad. Alves Baptista. São Paulo: Brasiliense.

BRASIL. Lei no 8.742, de 7 de dezembro de 1993. Dispõe sobre a organização da Assistência Social e dá outras providências. Diário Oficial da União, Brasília, DF, o8 dez. 1993.

Ministério da Saúde. Secretaria de Vigilância em Saúde. Monitoramento integrado de alterações no crescimento e desenvolvimento relacionado à infecção pelo vírus Zika e outras etiologias infecciosas, até a Semana Epidemiológica 52 de 2017. 2018.

COOK, Deborah. (2004). Adorno, Habermas and the Search for a Rational Society, New York: Routledge, p. 47.

CROCHÍK, José Leon. O desencanto sedutor: a ideologia da racionalidade tecnológica. Inter-Ação: Revista da Faculdade de Educação da UFG, Goiânia, v. 28, n. 1, p. 15-35, jan/jun. 2003.

DINIZ, Debora. (2012). O que é deficiência. São Paulo: Brasiliense.

DINIZ, Debora; BARBOSA, Lívia; SANTOS, Wederson Rufino dos. (2010) Deficiência, direitos humanos e justiça. In: DINIZ D.; SANTOS, W. (Org.). Deficiência e discriminação. Brasília: LetrasLivres: EdUnB. p. 97-115.

FEITOSA, I. M. L.; FACCINI, L. S.; SANSEVERINO, M. T. V. Aspectos importantes da Síndrome da Zika Congênita para o pediatra e o neonatologista. Boletim Científico de Pediatria, Rio Grande do Sul, v. 5, n. 3, 2016. 
FINE, Michael; GLENDINNING, Caroline. (2005). Dependence, Independence or inter-dependence? Revisiting the concepts of 'care' and 'dependency'. Ageing e Society, Cambridge University Prss, n. 25, p. 601-621.

GILLIGAN, Carol. (1982). Uma voz diferente: psicologia da diferença entre homens e mulheres da infância à idade adulta. Tradução Nathanael C. Caixeiro. Rio de Janeiro: Editora Rosa dos Tempos Ltda.

. (2013). La resistência a la injusticia: uma ética feminista del cuidado. In: GILLIGAN, C. (Org.). La ética del cuidado. Cuadernos de la Fundació Victor Grifols i Lucas.

GOFFMAN, E. Estigma - Notas sobre a manipulação da identidade deteriorada. Tradução Márcia Bandeira de Mello Leite Nunes. 4. ed. (reimpressão). Rio de Janeiro: LTC, 2017.

GUIMARÃES, Raquel. (2010). Gênero e deficiência: um estudo sobre as relações de cuidado. In: DINIZ, D.; SANTOS, W. (Org.). Deficiência e discriminação. Brasília: LetrasLivres, EdUnB. p. 197-228.

HORKHEIMER, Max. (2015). Teoria crítica: uma documentação. São Paulo: Perspectiva.

HORKHEIMER, Max; ADORNO, Theodor Wiesengrund. (1973). Sociedade. In: HORKHEIMER, M.; ADORNO, T. W. Temas básicos da Sociologia. Trad. Álvaro Cabral. São Paulo: Editora Cultrix - Editora da Universidade de São Paulo.

IBGE - Instituto Brasileiro de Geografia e Estatística. Censo Demográfico 2010. Dados Estatísticos. Disponível em: www.ibge.gov.br. Acesso em: 12 jan. 2018.

KITTAY, Eva. The Ethics of Care, Dependence, and Disability. (2011). Ratio Juris. v. 24, n. 1, p. 49-58, mar.

LAROSSA, Jorge. (2018). Tremores: escritos sobre experiência. Tradução: Cristina Antunes, João Wanderley Geraldi. 1. ed. 3. Reimp. Belo Horizonte: Autêntica Editora. (Coleção Educação: Experiência e Sentido).

MARQUES, Luciana Pacheco. (1995). O filho sonhado e o filho real. Revista Brasileira de Educação Especial, 3, 121-125.

MEDEIROS, Marcelo.; DINIZ, Debora. (2004). Envelhecimento e deficiência. In: Os novos idosos brasileiros: muito além dos 6o? CAMARANO, A. A. (Org.). Rio de Janeiro: IPEA. 
MEDEIROS, Marcelo.; BARROS, Fábio Granja.; NETO, Melchior Sawaya. (2010). Conceito de família do Benefício de Prestação Continuada. In: DINIZ, D.; MEDEIROS, M.; BARBOSA, L. (Org.). Deficiência e igualdade. Brasília: LetrasLivres, Editora Universidade de Brasília. p. 113-132.

MELLO, Anahi Guedes de.; NUERNBERG, Adriano Henrique. (2013). Corpo, gênero e sexualidade na experiência da deficiência: algumas notas de campo. In: SEMINÁRIO INTERNACIONAL ENLANÇANDO SEXUALIDADES, III., 2013, Salvador. Anais eletrônicos... Salvador: Universidade do Estado da Bahia.

MOURA, Claudia Helena Gonçalves. (2011). Experiência e Racionalidade: inspirações para uma educação crítica. Dissertação (mestrado). Universidade Federal de São João Del-Rei (UFSJ), Programa de Pós-Graduação em Psicologia da UFSJ. São Paulo.

NODDINGS, Nel. (2003). O cuidado: uma abordagem feminina a ética e a educação moral. Tradução Magda Lopes. 1. ed. São Leopoldo: Editora Unisinos.

NUSSBAUM, Martha. (2010). Capacidades e justiça social. In: DINIZ, Debora.; MEDEIROS, M.; BARBOSA, L. (Org.). Deficiência e igualdade. Brasília: LetrasLivres, Editora Universidade de Brasília. p. 21-42.

OLIVER, M.; BARNES, C (2012). The new politics of disablement. 2. Ed. Palgrave Macmillan.

PATTO, Maria Helena Souza. (2008). Vida cotidiana e preconceito: notas a partir da antropologia marxista de Agnes Heller. In: PATTO, M. H. S.; SCHIMDTI, M. L. S.; MELLO, S. L. de.; CROCHÎK, J. L. Perspectivas teóricas acerca do preconceito. São Paulo: Casa do Psicólogo. p. 9-25.

PETEAN, E. B. L.; MURATA, M. F. Paralisia cerebral: conhecimento das mães sobre o diagnóstico e o impacto deste na dinâmica familiar. Paidéia, Ribeirão Preto, v. 10, n. 19, ago/dez. 2000.

PICCOLO, Gustavo Martins.; MENDES, Enicéia Gonçalves. (2012). Nas pegadas da história: tracejando relações entre deficiência e sociedade. Revista Educação Especial, Santa Maria, v. 25, n. 42, p. 29-42, jan/abr.

TRONTO, Joan. (1997). Mulheres e cuidados: o que as feministas podem aprender sobre a moralidade a partir disso? In: JAGGAR, Alison; BORDO, Susan. (Org.). Gênero, corpo, conhecimento. Rio de Janeiro: Record, Rosa do Tempos. p. 186-203. 
VELHO, Gilberto. (2012). Desvio e divergência: uma crítica da patologia social. VELHO, G. (Org.). 2. ed. Rio de Janeiro: Zahar.

Recebido em 08/06/2020.

Aceito em 20/11/2020. 